\title{
Another crack at the porcelain aorta
}

\author{
Abe DeAnda, Jr, MD, ${ }^{\mathrm{a}}$ and Leora B. Balsam, $\mathrm{MD}^{\mathrm{b}}$

\footnotetext{
From the ${ }^{\mathrm{a}}$ Division of Cardiovascular and Thoracic Surgery, UTMB-Galveston, Galveston, Tex; and ${ }^{\mathrm{b}}$ Division of Cardiac Surgery, UMass Memorial Medical Center, Worcester, Mass.

Disclosures: Authors have nothing to disclose with regard to commercial support.

Received for publication April 9, 2018; accepted for publication April 9, 2018; available ahead of print May 9, 2018.

Address for reprints: Abe DeAnda, Jr, MD, Division of Cardiothoracic Surgery, UTMB-Galveston, 301 University Blvd, Galveston, TX 77551 (E-mail: abdeanda@utmb.edu).

J Thorac Cardiovasc Surg 2018;156:1035-6

$0022-5223 / \$ 36.00$

Copyright (c) 2018 by The American Association for Thoracic Surgery

https://doi.org/10.1016/j.jtcvs.2018.04.031
}

The language of medicine and surgery is replete with a colorful and descriptive lexicon. Terminology that is used to confer information to others may not have a fixed definition, leaving room for variable interpretation. For the surgeon, the words "hostile aorta" are such a term, reflecting a clinical situation that may directly affect the conduct of the operation. In general, the hostile aorta may describe the inability to safely crossclamp and/or cannulate the aorta, but it may also include anatomic considerations such as the aorta being stuck to the posterior plate of the sternum. A subclass of hostile aorta includes the descriptive "porcelain" aorta, which is generally discovered radiographically and contains partial or circumferential calcification of the media of the aorta. Amorim and colleagues ${ }^{1}$ have subdivided the types of porcelain aorta into $1 \mathrm{~A}$ (circumferential, not clampable), 1B (circumferential, possibly clampable), and 2 (involving the descending aorta with or without arch involvement). In general usage, the terms "hostile aorta" and "porcelain aorta" are interchangeable.

A hostile aorta may mean something different to vascular interventionalists than open cardiac surgeons, because intimal disease, such as the intraluminal calcifications of atherosclerosis, would be the worrisome entity. Manipulation of a wire or device during thoracic aortic endografting, transcatheter aortic valve replacement (TAVR), or percutaneous coronary interventions in the vicinity of such disease might dislodge atheromata, resulting in distal embolization. This intimal disease needs to be distinguished from the medial disease seen with porcelain aorta, because the risk of dislodging atheromata during wire manipulation is less with porcelain aorta; in this condition, dislodgement would primarily occur on cannulating or crossclamping the aorta, with extrusion of the medial disease into the lumen.

In this issue of the Journal, Nakasu and colleagues ${ }^{2}$ describe their experience and outcomes with TAVR in patients with a "hostile" ascending aorta. In a retrospective review of 665 consecutive patients undergoing TAVR, 36 patients $(5 \%)$ were identified as having a hostile aorta based on assessment of the preoperative computed tomography scan by the surgeon. In contrast, in the PARTNER

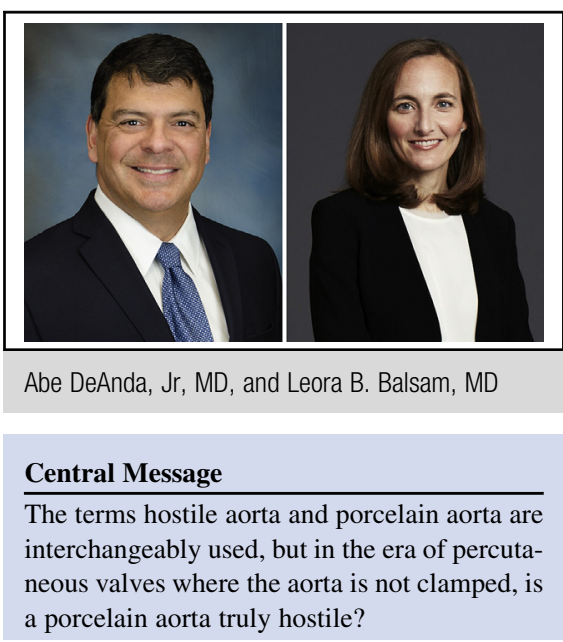

See Article page 1028.
(Placement of Aortic Transcatheter Valves) trial, 15.1\% of patients in the inoperable $\mathrm{arm}^{3}$ and $0.9 \%$ of patients in the TAVR versus high-risk surgical aortic valve replacement cohort ${ }^{4}$ were classified as having a porcelain aorta, defined in the study as complete or near-circumferential calcification of the ascending aorta or arch. ${ }^{5}$

In the current study, comparison of the 36 patients with a hostile aorta with the other 629 patients revealed no differences in operative mortality, mid-term (3 year) mortality, strokes, paravalvular leak, new-onset dialysis, new permanent pacemaker implantation, or vascular injury. It would appear that the hostile aorta and control groups were similar. But because porcelain aorta is a disease of the media, the presence of porcelain aorta in patients undergoing TAVR would not necessarily be expected to result in an increase in complications. This might explain why the 2 groups looked remarkably the same, at least statistically.

Nakasu and colleagues ${ }^{2}$ have provided us data to support TAVR in the setting of porcelain aorta, but what should not be lost are potential limitations of this study. Were the 2 groups different, ie, for endovascular procedures where the aorta is not going to be clamped do medial calcifications matter? A more meaningful but unlikely (and unnecessary) study would be a comparison of TAVR and open aortic valve replacement in the setting of porcelain aorta. Alternatively, a comparison of TAVR results in patients with and without intimal disease (excluding the calcified aortic root and annulus) that includes the distal aorta subjected to wire manipulation 
would provide an additional perspective. Importantly in an era in which procedures are performed opened and closed, we should consider a revision of our nomenclature; the words "hostile aorta" are not adequately descriptive for these high-stakes operations and procedures.

\section{References}

1. Amorim PA, Penov K, Lehmkuhl L, Haensig M, Mohr FW, Rastan AJ. Not all porcelain is the same: classification of circular aortic calcifications (porcelain aorta) according to the impact on therapeutic approach. Thorac Cardiovasc Surg. 2013; 61:559-63.
2. Nakasu A, Greason KL, Nkomo VT, Eleid MF, Pochettino A, King KS, et al. Transcatheter aortic valve insertion in patients with hostile ascending aorta calcification. J Thorac Cardiovasc Surg. 2018;156:1028-34.

3. Makkar RR, Jilaihawi H, Mack M, Chakravarty T, Cohen DJ, Cheng W, et al. Stratification outcomes after transcatheter aortic valve replacement according to surgical inoperability for technical versus clinical reasons. J Am Coll Cardiol. 2014;63:901-11.

4. Leon MB, Smith CR, Mack M, Miller DC, Moses JW, Svensson LG, et al. Transcatheter aortic-valve implantation for aortic stenosis in patients who cannot undergo surgery. N Engl J Med. 2010;363:1597-607.

5. Smith CR, Leon MB, Mack MJ, Miller DC, Moses JW, Svensson LG, et al. Transcatheter versus surgical aortic-valve replacement in high-risk patients. $N$ Engl J Med. 2011:364:2187-98. 